\title{
Fatores que influenciam no comportamento territorial de ribeirinhos sobre ambientes de pesca em áreas de várzea do baixo Solimões, Amazônia Central, Brasil Factors that affect riverines territorial behavior on fishing environments in flooding areas, Low Solimões, Central Amazonia, Brazil
}

\author{
Danielle Sequeira Garcez \\ Jorge Iván Sánchez-Botero"I \\ Nidia Noemi FabréllI
}

\begin{abstract}
Resumo: Regiões de várzea apresentam alta produtividade biológica e são habitadas por populações que praticam atividades agropesqueiras, baseadas no uso múltiplo dos recursos. A economicidade do sistema conduz os ribeirinhos à apropriação de territórios e a dependência conjunta dos recursos ao estabelecimento de acordos internos, definindo-se critérios de acesso e intensidades de extração. Este estudo, por meio de 244 entrevistas com pescadores e reuniões em 16 comunidades do baixo Solimões, identificou fatores que influenciam na magnitude e finalidade das pescarias, especialmente em pesqueiros de uso coletivo, descrevendo mecanismos de apropriação e conflitos. $O$ trecho abriga dois sistemas de lagos de terra firme e um de lagos de várzea. Para pescarias de subsistência e comercial, foram estimadas área, extensão e frequência de uso por período do ano (seca/cheia). Cada comunidade explorou os ambientes de pesca de acordo com a proximidade e/ou acessibilidade, revelando uso dentro das delimitações territoriais, havendo sobreposição naqueles explorados para subsistência e comércio. Existem conflitos por pesca comercial, esportiva, com pescadores externos à comunidade e com fazendeiros. Não existem proibições ou controle de acesso aos igapós, mas regras informais. Para o manejo integrado na área de estudo, são propostos três cenários de atuação, considerando a diversidade de ambientes e os interesses dos grupos envolvidos.
\end{abstract}

Palavras-chave: Comunidades ribeirinhas. Territorialidade. Acordos de pesca. Manejo. Manacapuru. Rio Solimões.

Abstract: Flooding areas present high biological productivity and are inhabited by populations that practice agriculture-fishing activities, based on the multiple use of resources. The economicity of the system leads the riverines to territorial appropriation and the common dependence of the resources leads to the establishment of internal agreements, defining criteria of access and intensity of extraction. This study, through 244 interviews with fishermen and meetings at 16 communities of Low Solimões River, identified factors that influence on the magnitude and purpose of the fisheries, especially at common use fishing spots, describing appropriation mechanisms and conflicts. The studied area comprehends two systems of terra firme and one of flooding lakes. For subsistence and commercial fisheries was estimated the area, extension, and frequency of use for period of the year (dry/flood). Each community explored the fishing environments depending on the proximity and/or accessibility, revealing uses inside its territorial delimitations, with superposing on that explored for subsistence and commercial means. There are conflicts with commercial and sporting fisheries, fishermen out from the region and farmers. Prohibitions or access control don't exist to the igapós systems, but informal rules regulating the use. Three sceneries are proposed for the integrated management of the systems in the area, due to the diversity of environments and interests of the involved groups.

Keywords: Riverine communities. Territoriality. Fishing agreements. Management. Manacapuru. Solimões River.

l Universidade Federal do Ceará. Instituto de Ciências do Mar. Fortaleza, Ceará, Brasil (dsgarcez@gmail.com).

"I Universidade Federal do Ceará. Departamento de Biologia. Centro de Ciências. Fortaleza, Ceará, Brasil (jisbar@gmail.com).

III Universidade Federal de Alagoas. Centro de Ciências Biológicas e da Saúde. Maceió, Alagoas, Brasil (tchoni1@uol.com.br).

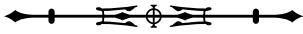




\section{INTRODUÇÃO}

As regiões de várzea amazônica, que são faixas de terras marginais aos rios, constituem-se em terrenos periodicamente cobertos pelas águas brancas e apresentam alto potencial de produtividade biológica (Junk, 1983). Devido à elevada fertilidade de seus solos, essas áreas têm sido habitadas desde o período anterior à colonização europeia por populações que praticam atividades de subsistência, baseadas em estratégia de uso múltiplo dos recursos, cultivando espécies de ciclos curtos, complementadas com a caça, a criação de animais e a pesca (Furtado, 1993; Cerdeira et al., 1997; Ruffino, 2005).

Durante o período de ocupação portuguesa, a política de dominação na região amazônica resultou na formação dos primeiros núcleos coloniais, e os processos histórico, econômico, social e cultural, somados às características ambientais da região, deram origem à formação de uma sociedade cabocla de caráter basicamente agropesqueiro (Furtado, 1993; Ruffino, 2005).

O estabelecimento e a manutenção das comunidades ribeirinhas têm como fator fundamental a diversidade de ambientes propícios à pesca, os quais são explorados com ou sem fins de comercialização do pescado (Furtado, 1993; McGrath et al., 1993a, 1998; Ruffino e Isaac, 1994; Ruffino et al., 1999; McDaniel, 1997; Da Costa et al., 1999; Batista e Fabré, 2003; Santos e Santos, 2005).

A economicidade do sistema, seja para garantia da subsistência dos indivíduos que dele se utilizam ou para valor de troca (Dyson-Hudson e Smith, 1978), conduz os ribeirinhos à apropriação de territórios. Essa forma de comportamento, definida em ecologia como controle e defesa de determinada área (Ricklefs, 1996), faz com que as comunidades assumam um direito de propriedade sobre os recursos que lhes são mais aproximados por meio de dominação imposta por regras informais (Furtado, 1993; Marques, 1995; Begossi, 1998; Pereira, 1999; Ribeiro e Fabré, 2003; Ruffino, 2005). A dependência conjunta do mesmo recurso ambiental conduz ao estabelecimento de acordos internos entre as comunidades ribeirinhas, as quais definem os critérios de acesso aos recursos e a intensidade de extração destes. Destas regulamentações resultam as Instituições de Propriedade Coletiva, responsáveis por definir o funcionamento do manejo de recursos de uso comum, podendo as comunidades desenvolver, todavia, níveis diferenciados segundo os interesses locais (Ostrom, 1990; Begossi, 1998; Pereira, 1999; Lima, 2005; Ruffino, 2005).

O dinamismo aquático da várzea, manifestado na complexidade de exploração ambiental pelos habitantes dessa região (Morán, 1990), exige programas de manejo integrado dos sistemas que sejam direcionados, pois a escala é um fator fundamental para as relações humanas com o meio (Begossi, 1998), somado ao fato de a especificidade e a diversidade das situações de pesca na Amazônia requererem atenções particularizadas (Leonel, 1998; Ruffino, 2005; Santos e Santos, 2005).

Como as atitudes em relação à natureza refletemse na maneira pela qual as sociedades se organizam para explorar os seus recursos (Holling et al., 1998; Lima e Pozzobon, 2005), o presente estudo identificou fatores que influenciam na magnitude e finalidade das pescarias praticadas por comunidades em áreas de várzea, com atenção aos pesqueiros de uso coletivo, descrevendo mecanismos de apropriação, conflitos existentes e atitudes adotadas pelos comunitários.

\section{MATERIAL E MÉTODOS}

O presente estudo foi realizado em uma zona rural do município de Manacapuru, localizado a 68 km de Manaus e com área total de $7.367,9$ km², numa extensão linear de, aproximadamente, $35 \mathrm{~km}$ na margem direita do rio Solimões, estado do Amazonas (03 39' S; 60 49' W a $03^{\circ} 22^{\prime} \mathrm{S} ; 60^{\circ} 41^{\prime} \mathrm{W}$ ). A área se divide em duas zonas principais: costa do Canabuoca (desde os lagos JacaréParacuúba até o paraná do Mari) e costa do Marrecão (até o igarapé do Siro), que abrigam um total de 17 comunidades (Figura 1). Caracteriza-se por ser um trecho contínuo de várzea, portanto, sujeito aos processos de flutuação do nível das águas (Junk et al., 1989). Esta

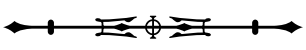




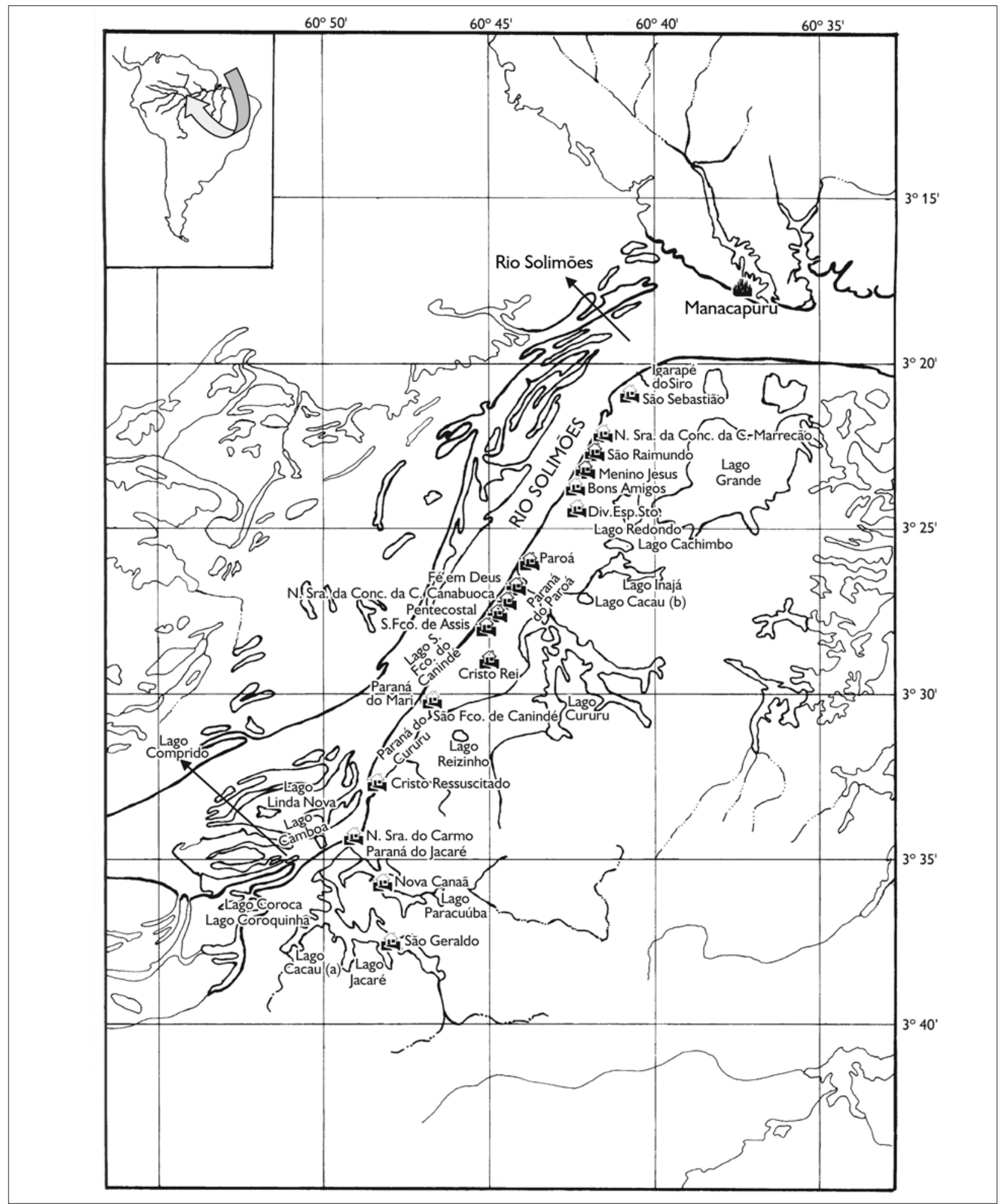

Figura 1. Comunidades e ambientes enfocados nesse estudo, com amostras da exploração pela pesca de subsistência e comercial.

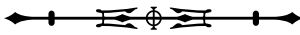


oscilação entre as fases terrestre e aquática (Junk et al., 1989) promove mudanças ambientais, permitindo usos múltiplos do sistema, fato que exige adaptação dos moradores ribeirinhos para otimizar o aproveitamento dos recursos disponíveis nas diversas fases do ano.

A área abriga dois sistemas de lagos de terra firme e um sistema de lagos de várzea. Entre os primeiros, estão dois grandes lagos, Jacaré e Paracuúba $\left(27,7 \mathrm{~km}^{2}\right)$, os quais se comunicam através de um pequeno estreito denominado 'Repartimento'. No entanto, a principal via de acesso aos lagos é o paraná do Jacaré, de comunicação direta com o rio Solimões, na altura da comunidade Nossa Senhora do Carmo. O segundo sistema é composto pelo lago Cururu $\left(35,1 \mathrm{~km}^{2}\right)$, associado a mais dois lagos sem nominações distintas. Ambos os sistemas são providos de grandes extensões de paranás (canais de comunicação do rio com os lagos de terra firme), como o do Jacaré $(4,1 \mathrm{~km})$, do Mari (2,7 km), do Paroá (3,5 km) e do Cururu $(9,6$ km). 0 terceiro sistema lacustre está representado pelo lago Grande $\left(28,3 \mathrm{~km}^{2}\right)$, associado a três lagos menores no seu entorno: Cachimbo $\left(0,5 \mathrm{~km}^{2}\right)$, Redondo $\left(3 \mathrm{~km}^{2}\right)$ e Inajá $\left(7,2 \mathrm{~km}^{2}\right)$.

Além desses sistemas lacustres, estão distribuídos na região mais 14 lagos de várzea explorados para a pesca e cuja área média é de 0,6 km²: lagos Cacau (dois lagos distintos, de mesmo nome, em localizações diferentes, sinalizados como a e b), Cachimbo, Camboa, Coroca, Coroquinha, Comprido, Galo, Linda Nova, Reizinho e quatro sem nomes específicos: um localizado em frente à comunidade São Francisco do Canindé e três na margem esquerda do rio Solimões, em frente ao sistema do lago Grande (Figura 1). $O$ alto desvio padrão encontrado na estimativa média total da área dos lagos de várzea deve-se ao fato deste sistema apresentar lagos de tamanhos que variam de 0,5 km² a 28,3 km² (sendo 0,5 km² o tamanho mais frequentemente encontrado) (Tabela 1). De acordo com suas origens geológicas, os lagos Jacaré, Paracuúba e Cururu são caracteristicamente de barragem, alongados, dendríticos e irrigados por igarapés de terra firme, enquanto que o lago Grande é típico de várzea, recebendo principalmente as águas do rio principal.
Tabela 1. Dimensão dos ambientes disponíveis para ambos os tipos de pesca, registrados na área de estudo $(C=$ pertencente à costa do Canabuoca; $M$ = pertence à costa do Marrecão).

\begin{tabular}{|c|c|c|}
\hline $\begin{array}{l}\text { Lagos de } \\
\text { terra firme }\end{array}$ & $\begin{array}{l}\text { Área } \\
\left(\mathrm{km}^{2}\right)\end{array}$ & $\begin{array}{l}\text { Coordenadas } \\
\text { geográficas } \\
(\mathrm{LS} \text { e LW) }\end{array}$ \\
\hline 1. Jacaré (C) & 16,8 & $3^{\circ} 39^{\prime} ; 60^{\circ} 48^{\prime}$ \\
\hline 2. Paracuúba (C) & 10,9 & $3^{\circ} 37^{\prime} ; 60^{\circ} 48^{\prime}$ \\
\hline 3. Cururu (C) & 35,1 & $3^{\circ} 29^{\prime} ; 60^{\circ} 43^{\prime}$ \\
\hline Área total & 62,8 & \\
\hline Tamanho médio e desvio & $20,9 \pm 12,6$ & \\
\hline Lagos de várzea & Área $\left(\mathrm{km}^{2}\right)$ & \\
\hline 1. Cacau (a: C e b: M) & 1 & $3^{\circ} 37^{\prime} ; 60^{\circ} 50^{\prime}$ \\
\hline 2. Coroca $(\mathrm{C})$ & 0,5 & \\
\hline 3. Coroquinha $(C)$ & 0,5 & \\
\hline 4. Linda Nova (C) & 0,5 & \\
\hline 5. Comprido (C) & 0,5 & \\
\hline 6. Galo (C) & 0,5 & \\
\hline 7. Camboa (C) & 1,5 & $3^{\circ} 35^{\prime} ; 60^{\circ} 50^{\prime}$ \\
\hline 8. Reizinho (C) & 0,5 & \\
\hline 9. São Francisco do Canindé $(C)$ & 0,5 & $3^{\circ} 32^{\prime} ; 60^{\circ} 47^{\prime}$ \\
\hline 10. Inajá (M) & 7,2 & $3^{\circ} 27^{\prime} ; 60^{\circ} 39^{\prime}$ \\
\hline 11. Cachimbo (M) & 0,5 & \\
\hline 12. Redondo (M) & 3 & $3^{\circ} 25^{\prime} ; 60^{\circ} 40^{\prime}$ \\
\hline 13. Grande (M) & 28,3 & $3^{\circ} 26^{\prime} ; 60^{\circ} 38^{\prime}$ \\
\hline 14. sem nome (três lagos) (M) & 1,5 & \\
\hline Área total & 46,5 & \\
\hline Tamanho médio e desvio & $2,7 \pm 6,8$ & \\
\hline Paranás & Extensão $(\mathrm{km})$ & \\
\hline 1. Jacaré (C) & 4,1 & $3^{\circ} 35^{\prime} ; 60^{\circ} 49^{\prime}$ \\
\hline 2. Cururu (C) & 9,6 & \\
\hline 3. Mari (C) & 2,7 & $3^{\circ} 32^{\prime} ; 60^{\circ} 47^{\prime}$ \\
\hline 4. Paroá (M) & 3,5 & $3^{\circ} 27^{\prime} ; 60^{\circ} 44^{\prime}$ \\
\hline Extensão total & 19,9 & \\
\hline Tamanho médio e desvio & $4,6 \pm 2,8$ & \\
\hline Igarapé & Extensão $(\mathrm{km})$ & \\
\hline 1. Siro (M) & 0,9 & $3^{\circ} 22^{\prime} ; 60^{\circ} 41^{\prime}$ \\
\hline
\end{tabular}

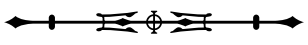


A região em estudo está composta, ainda, por praias, matas de várzea, chavascais e matas de terra firme. Os paranás, além de serem canais de navegação até os lagos, são importantes ambientes para a migração/dispersão de peixes entre lagos e rio, e, portanto, bastante explorados pela atividade pesqueira. As praias são extensos bancos de areia formados nas margens do rio em consequência da descida do nível das águas ou pelo acúmulo de sedimentos (Sioli, 1968; Goulding, 1997), sendo paisagens extremamente dinâmicas, cujas localização e extensão estão sujeitas a mudanças. São utilizadas pelos moradores para pesca no canal principal do rio e para a coleta de ovos depositados por tracajás e gaivotas.

As restingas são fragmentos de florestas localizados nas porções mais altas da várzea (Ayres, 1995). Na região de estudo, parte dela (entre 200 e 300 m de extensão em direção à terra firme) foi desmatada para a construção e o estabelecimento das moradias, para a disponibilização de áreas para o plantio e a criação de gado nos períodos de seca. $\bigcirc$ principal produto cultivado nestas áreas é a mandioca, seguida pela macaxeira, milho, feijão e malva; os rebanhos são constituídos por gado mestiço ou das raças Nelore, Holandês e Gir. Durante o período de cheia, as áreas de várzea da restinga tornam-se um sistema único completamente alagado, configurando formações regionalmente denominadas como igapós, os quais são utilizados pela população principalmente para a pesca. Porém, alguns habitantes aproveitam este período de áreas inundadas para a retirada de madeira da mata, devido à maior facilidade para o transporte.

Os chavascais são constituídos por extensas áreas de vegetação arbustiva e pantanosa, sendo comuns na região entre o canal dos rios e os lagos, posicionados normalmente atrás das faixas de restinga. Nessas áreas de relevo caracteristicamente baixio, concentra-se um tipo de palmeira (Astrocaryum jauari Mart.) cujos frutos são utilizados na pesca do tambaqui (Ayres, 1995; Araújo-Lima e Goulding, 1998). As matas de terra firme estão localizadas nas áreas mais altas do relevo, não sujeitas a inundação, nas quais há extração de produtos da mata (como madeira, folhas e frutos), sendo praticada a caça de animais (como capivaras, antas, queixadas, pacas, cutias, tatus e veados) (Figura 2).

Foi empregada a metodologia de pesquisa Levantamento Rápido Rural (LRR) (Dunn, 1994; Mitlewski, 1999; Verdejo, 2006), seguindo duas estratégias: 1) entrevistas não estruturadas, por meio de reuniões com comunitários previamente convocados, elaborando-se mapas mentais (Gould e White, 1974), ressaltando detalhadamente os ambientes dentro da área ocupada pela comunidade (lagos, paranás, furos, igarapés, áreas de restinga, chavascais, terra firme, entre outros) e extensões aproximadas, os recursos explorados, as atividades produtivas (agricultura, pesca, pecuária, extrativismo vegetal), a localização de moradias, igrejas e demais centros comuns, bem como a descrição das ações comunitárias e dos conflitos existentes (aqui compreendidos como a sobreposição de interesses sobre áreas de uso comum, por grupos distintos); 2) entrevistas por meio de questionários semiestruturados aplicados à população em geral e, especificamente, a pescadores comerciais.

O posicionamento geográfico das comunidades foi determinado com o uso de um aparelho GPS, em frente aos locais-sede. Para as localizações cartográficas, foram utilizados o mapa da região Norte do Brasil, Folha SA.20-Z-D, MIR 115, de escala 1: $250.000(1 \mathrm{~mm}=250 \mathrm{~m})$ e a imagem de radar NASDA JERS-1 SAR (set.-dez./1995), criada no âmbito do Projeto "Global Rain Forest Mapping Project South America" (resolução espacial aproximada de 0,01 km²).

O trabalho de campo foi realizado entre julho de 1998 e setembro de 1999, sendo efetuadas quatro saídas de campo, com duração média de 12 dias cada (agosto-setembro/1998, novembro/1998, março/1999 e agosto/1999), tendo sido visitadas 16 comunidades e realizada uma reunião comunitária em cada uma, totalizando 187 entrevistas com pescadores de subsistência (considerando-se aleatoriamente 30\% do total de casas existentes por comunidade) e 57 com pescadores comerciais (que se dedicam à atividade pesqueira com fins comerciais em pelo menos um período do ano). Foram entrevistados todos os pescadores comerciais 


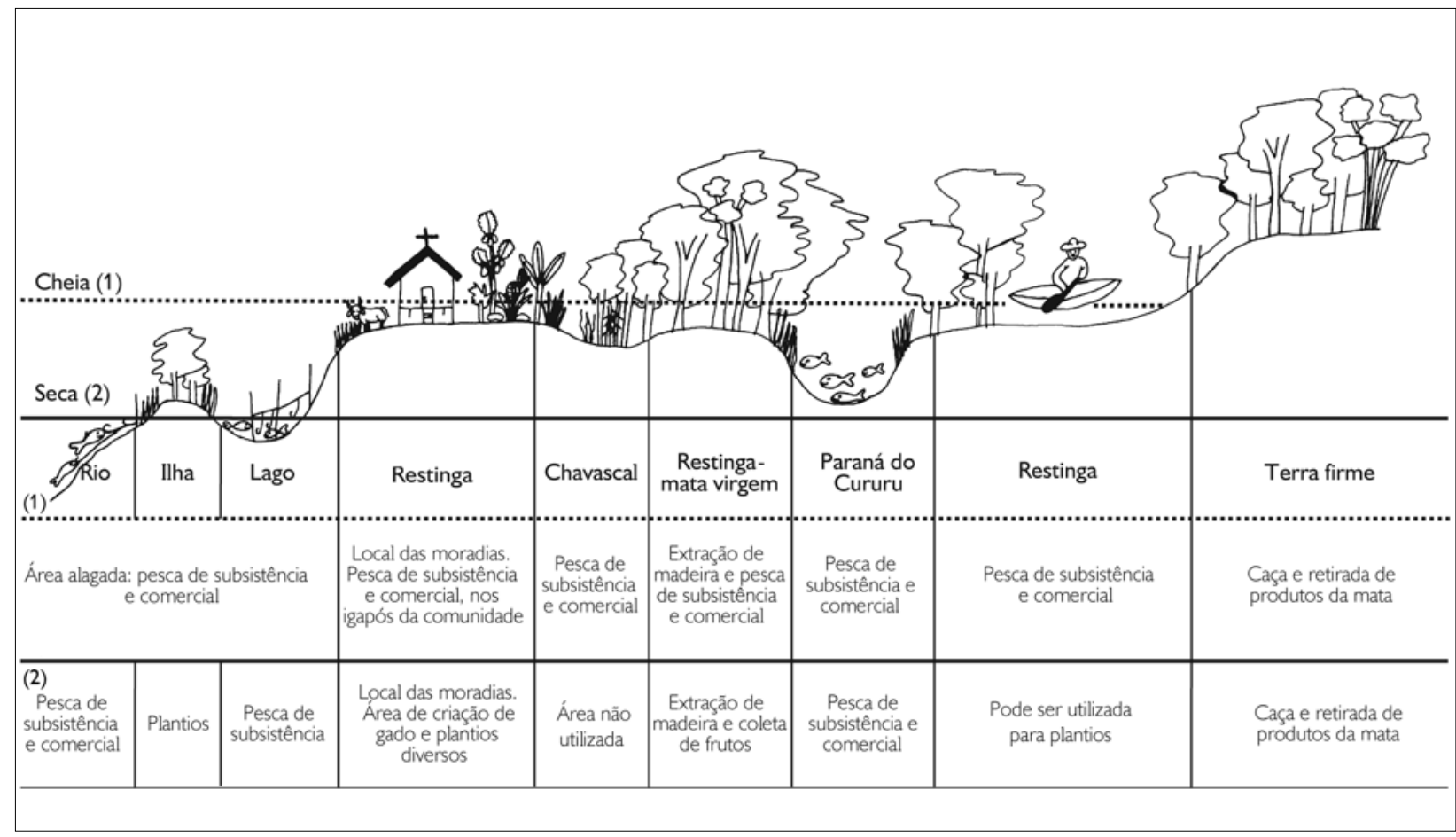

Figura 2. Perfil ambiental de uma comunidade na área de estudo, com exemplo do uso múltiplo dos ambientes.

dos locais visitados, excetuando-se parentes ou vizinhos que praticassem a atividade em conjunto. Aqueles não localizados foram contabilizados e incluídos no total de pescadores comerciais por comunidade.

Para ambos os tipos de pescaria (subsistência ou comercial) foram estimadas área e extensão dos locais de pesca explorados e sua frequência de uso por período do ano (seca ou cheia). Os meses de novembro/dezembro/janeiro e maio/junho/julho foram definidos caracteristicamente na região como sendo períodos de seca e cheia, respectivamente. Os lagos não localizados no mapa e a imagem de radar tiveram área estimada em 0,5 km² (escala mínima para apresentação na imagem) e foram plotados com base nos mapas mentais ou indicação dos moradores.

Foi realizado um teste t para comparar o número de locais explorados pelas comunidades por tipo de pescaria (subsistência e comercial). A descrição de conflitos e mecanismos adotados para resoluções baseou-se nas reuniões comunitárias e nos resultados dos mapas mentais.

\section{ASPECTOS DEMOGRÁFICOS}

As comunidades consideradas neste estudo abrigam um total de 365 residências, com 2.005 pessoas, sendo a população composta por 34,1\% de homens, $25,4 \%$ de mulheres e $40,5 \%$ de crianças (abaixo de 12 anos de idade) (Tabela 2). Setenta e dois por cento dos chefes de família entrevistados são provenientes de áreas rurais, nascidos na própria comunidade ou em localidades próximas. $O$ censo das comunidades Nossa Senhora da Conceição da costa do Canabuoca e Fé em Deus foi tratado conjuntamente em virtude delas estarem próximas e sem separação delimitada das residências. Outras três comunidades não foram contabilizadas no total: 1) Nova Canaã, dispersa ao longo do lago Paracuúba, com moradores vivendo isolados, sem liderança comunitária e cujo sustento provém da agricultura, caça e pesca; 2) Cristo Rei, que ocupa uma área de aproximadamente $3.000 \mathrm{~m}^{2}$, abrigando uma fazenda de gado na qual os moradores dedicam-se

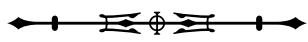


Tabela 2. Censo populacional estimado por visitação de residências (VR) e por meio de reuniões comunitárias (RC).

\begin{tabular}{|c|c|c|c|c|c|c|c|c|}
\hline & \multirow[b]{2}{*}{ Comunidade } & \multicolumn{2}{|c|}{ Metodologia } & \multicolumn{5}{|c|}{ Habitantes } \\
\hline & & VR & $\mathrm{RC}$ & $\begin{array}{c}\text { população } \\
\text { total* }\end{array}$ & homens & mulheres & crianças & residências \\
\hline \multirow{7}{*}{ 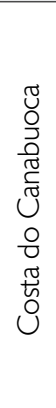 } & São Geraldo & 190 & - & 190 & 60 & 30 & 100 & 38 \\
\hline & Nossa Senhora do Carmo & 393 & - & 393 & 100 & 104 & 189 & 71 \\
\hline & Cristo Ressuscitado & 251 & 216 & $234 *$ & 90 & 60 & 101 & 53 \\
\hline & São Francisco do Canindé & 214 & 214 & $214 *$ & 82 & 62 & 70 & 34 \\
\hline & São Francisco de Assis & 172 & 266 & $219^{*}$ & 57 & 46 & 69 & 32 \\
\hline & Pentecostal do Brasil & 121 & 81 & $101 *$ & 39 & 36 & 46 & 15 \\
\hline & $\begin{array}{l}\text { Nossa Senhora da } \\
\text { Conceição e Fé em Deus }\end{array}$ & 199 & - & 199 & 72 & 53 & 74 & 32 \\
\hline \multirow{7}{*}{ 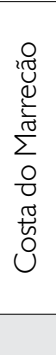 } & Paroá & 88 & - & 88 & 33 & 28 & 27 & 12 \\
\hline & Divino Espírito Santo & 75 & - & 75 & 29 & 20 & 26 & 12 \\
\hline & Menino Jesus & 31 & - & 31 & 9 & 6 & 16 & 6 \\
\hline & São Raimundo & 100 & - & 100 & 44 & 28 & 28 & 15 \\
\hline & Nossa Senhora da Conceição & 55 & - & 55 & 26 & 17 & 12 & 10 \\
\hline & São Sebastião & 106 & - & 106 & 39 & 31 & 36 & 20 \\
\hline & Total & - & - & 2005 & 684 & 510 & 811 & 365 \\
\hline
\end{tabular}

*Valores médios entre ambas metodologias.

à criação de 400 cabeças (Nelore, Holandês e Gir), composta por 12 residências e com um total de 82 pessoas (33 homens, 22 mulheres e 27 crianças); 3) Bons Amigos, composta por aproximadamente dez famílias vivendo principalmente da agricultura.

\section{RESULTADOS}

\section{AMBIENTES EXPLORADOS PELA PESCA DE SUBSISTÊNCIA}

Cada uma das comunidades explorou os ambientes de pesca de acordo com a proximidade e/ou acessibilidade a estes, revelando uma tendência de uso dentro de suas delimitações territoriais, sem grande diferença por período de seca ou cheia. $\bigcirc$ ambiente rio, de uma maneira geral, foi frequentemente explorado por todas as comunidades. Os lagos de terra firme foram mais explorados pelas comunidades São Geraldo e Nossa Senhora do Carmo, decrescendo a sua utilização nas duas comunidades subsequentes e aumentando novamente nas comunidades São Francisco de Assis e Paroá. Esta tendência de uso coincide com a existência dos dois sistemas de lagos de terra firme na região: Jacaré-Paracuúba e Cururu (Figura 3).

Como indicado na frequência relativa de exploração dos ambientes de pesca (Figura 3), quando houve diminuição da exploração dos lagos de terra firme, aumentou a frequência de uso dos paranás e lagos de várzea pelas comunidades centralizadas entre ambos os sistemas, ou seja, estas estão explorando os ambientes disponíveis na parte posterior à sua ocupação. Entretanto, os lagos de várzea foram explorados em menor escala pelas comunidades que possuíam lagos de terra firme no seu entorno. Porém, a não existência de lagos de terra firme e o decrescimento na abundância de paranás a partir da comunidade Divino Espírito Santo fazem com que, deste ponto em diante, os lagos de várzea, principalmente do 

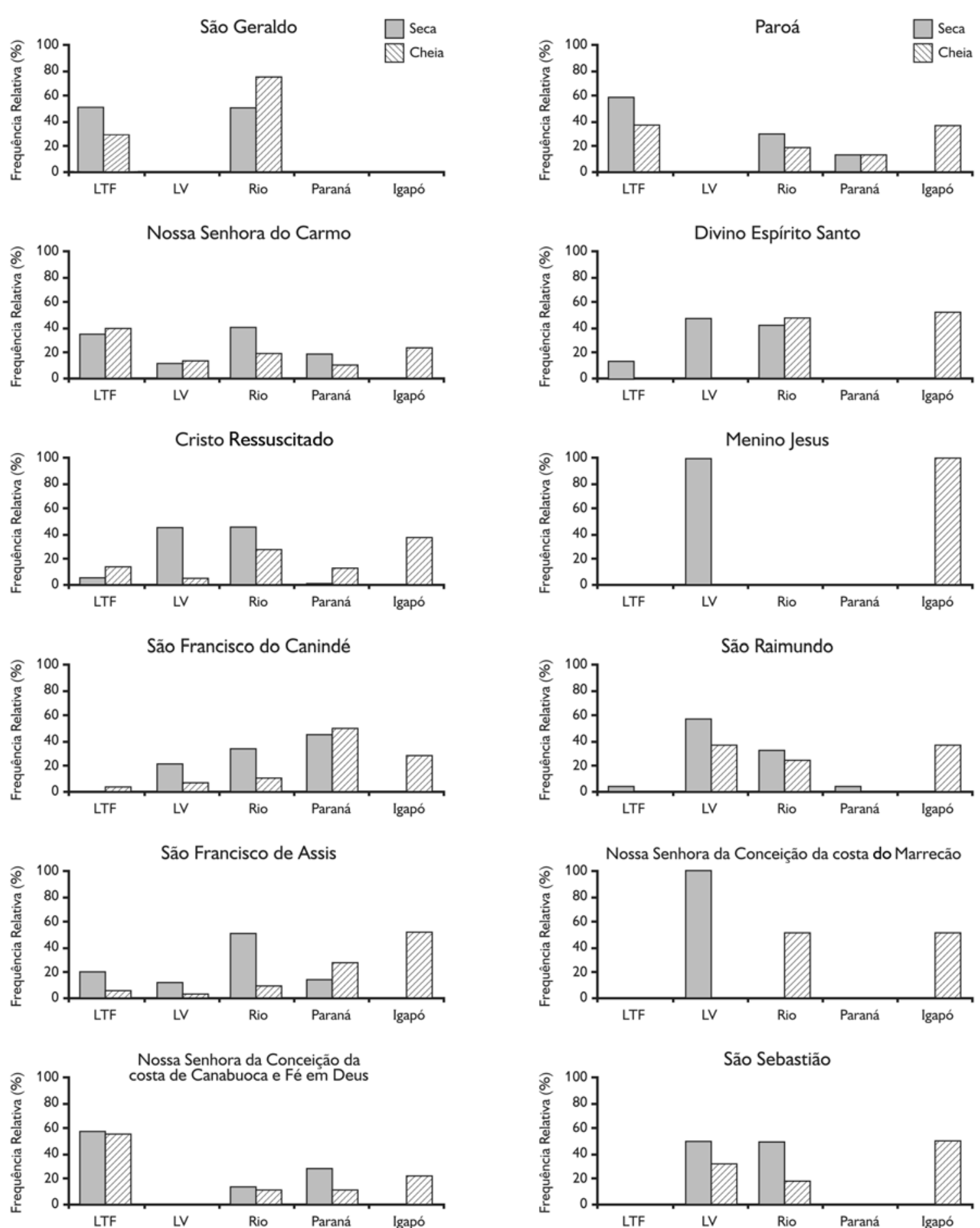

Figura 3. Frequência relativa de ambientes explorados pela pesca de subsistência, por comunidade e período (LTF = lagos de terra firme; $\mathrm{LV}=$ lagos de várzea).

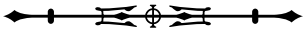


sistema lago Grande, passem a ser mais utilizados para a pesca pelas comunidades Menino Jesus, São Raimundo, Nossa Senhora da Conceição, da costa do Marrecão, e São Sebastião. Este fato corrobora a tendência observada de uso daqueles sistemas localizados nas proximidades da comunidade. Os igapós mostraram-se frequentemente explorados por todas as comunidades na época de cheia, principalmente dentro da área geográfica pertencente a cada uma, à exceção da São Geraldo, onde a pesca se concentra no próprio lago e no rio (Figura 3).

\section{OS AMBIENTES EXPLORADOS PELA PESCA COMERCIAL}

A atividade pesqueira comercial foi realizada apenas em ambientes pertencentes ao sistema, cuja permissão foi dada pela comunidade para este fim. Os lagos de terra firme do sistema Jacaré-Paracuúba foram explorados com fins comerciais, com alta frequência, apenas pela comunidade São Geraldo, que está localizada na parte interior do lago Jacaré. Esses lagos não são facilmente acessíveis no período de seca e não foram explorados pelas comunidades Nossa Senhora do Carmo e Cristo Ressuscitado, aquelas localizadas mais próximas. Para compensar a não acessibilidade a estes sistemas, a comunidade Cristo Ressuscitado, que possui o maior número de pescadores comerciais, explora com maior frequência o rio e os lagos de várzea próximos à comunidade (Figura 4).

As duas comunidades subsequentes, São Francisco do Canindé e de Assis, exploram mais frequentemente os paranás para realização de suas pescarias, enquanto que estes ambientes não são explorados com fins de comercialização pelas comunidades da costa do Marrecão. As comunidades Nossa Senhora da Conceição, da costa do Canabuoca, e Fé em Deus, mesmo com acesso aos paranás, exploram na seca principalmente o lago de terra firme do Cururu, provavelmente em consequência da maior produtividade deste ambiente quando em comparação aos paranás. A comunidade do Paroá utilizouse somente do rio para as pescarias comerciais (Figura 4).
Entretanto, o baixo número amostral de entrevistas nesta comunidade pode não ter detectado uso de outros ambientes. De qualquer forma, seu paraná de acesso ao lago Cururu seca quase por completo no período de águas baixas, dificultando o deslocamento dos moradores e impossibilitando a passagem dos peixes.

Os lagos de várzea foram ambientes de uso frequente pelas comunidades da costa do Marrecão, e os igapós foram explorados por todas as comunidades. No entanto, são parcialmente respeitadas as dimensões espaciais concernentes ao território da comunidade. Não aparecem como áreas exploradas pelas comunidades São Geraldo e Nossa Senhora do Carmo porque estas estão localizadas em regiões mais altas, de terra firme, consequentemente, sem inundações no período de subida das águas. Para as demais comunidades, os igapós, frequentemente explorados para a pesca, configuraramse como importantes locais para a geração de renda no período da cheia (Figura 4).

\section{MECANISMOS DE APROPRIAÇÃO EM RELAÇÃO AOS LOCAIS DE PESCA ADOTADOS PELAS COMUNIDADES}

A pesca de subsistência é praticada em um número significativamente superior de locais quando comparada à comercial ( $t_{\text {obs }}=2,774 ; p=0,018$ ) (Figura 5). Tais locais, no entanto, não estão restritos ao uso por apenas uma comunidade, sendo de uso compartilhado por aquelas mais próximas.

Em relação aos pesqueiros de uso comum, foi identificado que uma ou mais comunidades adotam algum tipo de comportamento, regulamentando as formas de uso. O conjunto de mecanismos de apropriação identificados variou de acordo com as comunidades integrantes de cada sistema de lagos e em função dos conflitos existentes (Tabela 3). Relacionam-se principalmente à proibição, à restrição ou ao controle das áreas e dos recursos pesqueiros.

No sistema Jacaré-Paracuúba, foram identificados conflitos entre líderes locais/moradores e pescadores

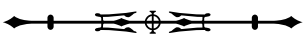



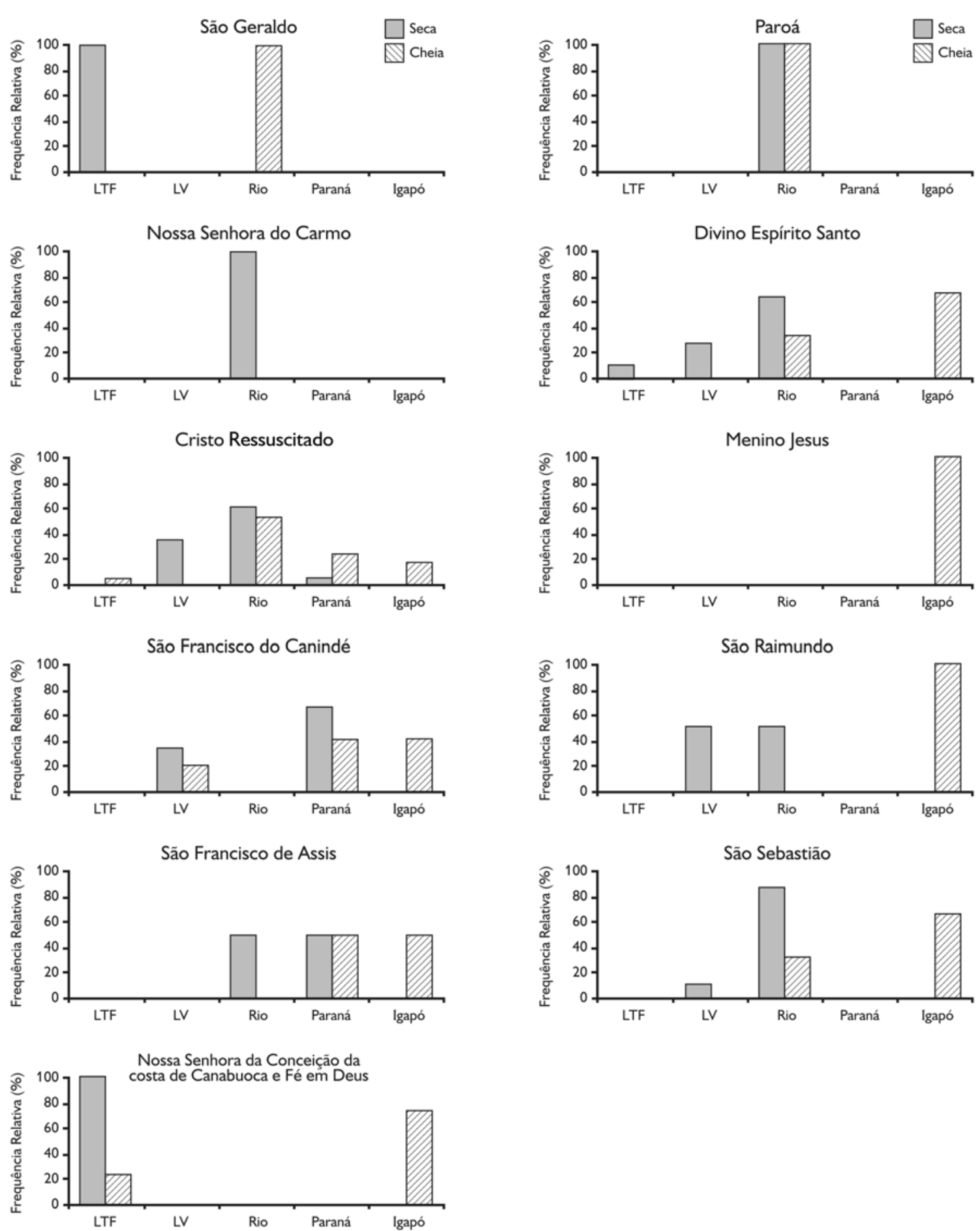

Figura 4. Frequência relativa de ambientes explorados pela pesca comercial, por comunidade e período (LTF = lagos de terra firme; LV = lagos de várzea).

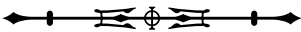




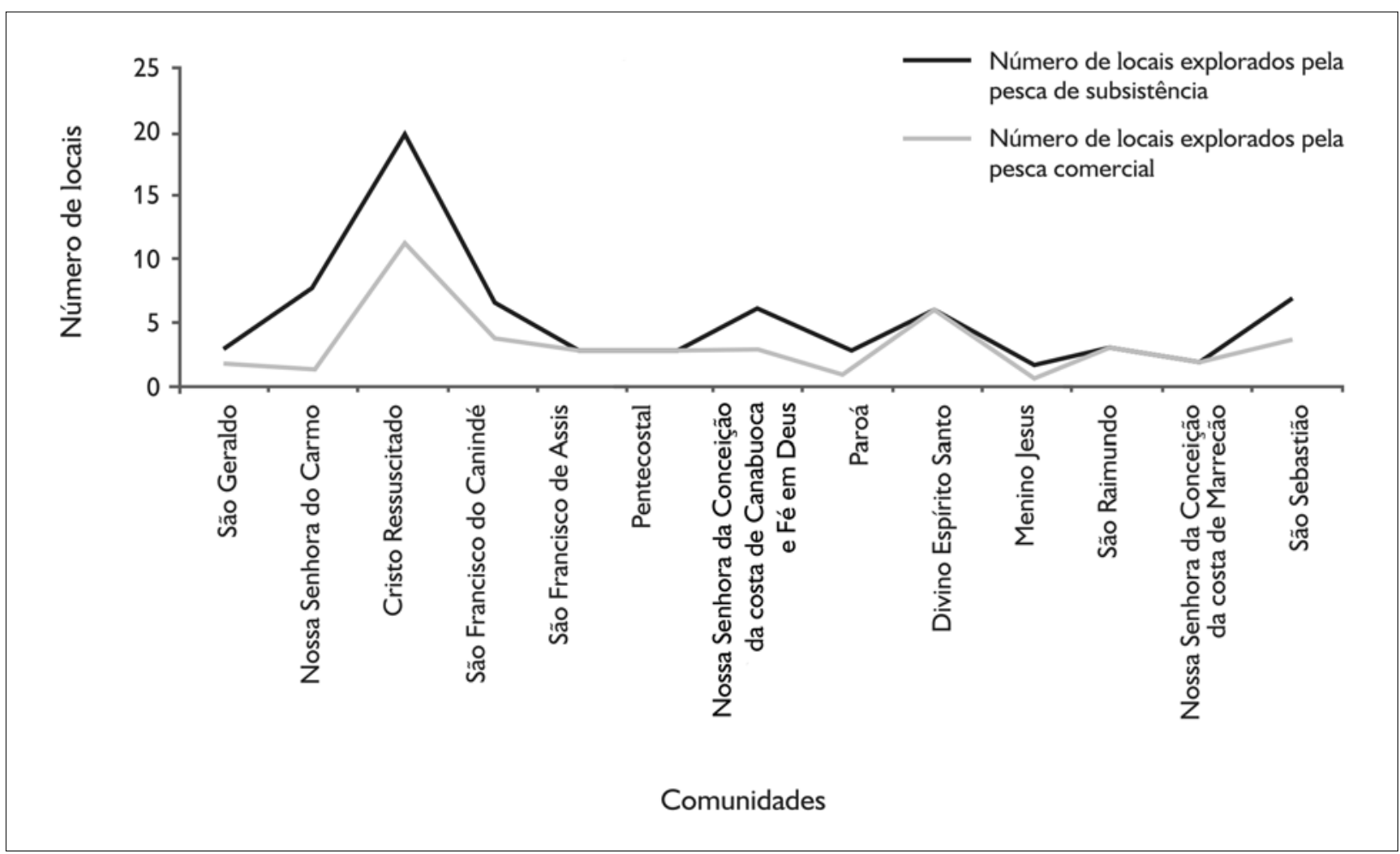

Figura 5. Número de locais explorados pela pesca de subsistência e comercial nas comunidades estudadas.

comerciais, pois o primeiro grupo não permite que os lagos sejam utilizados com fins comerciais no período de seca. Os líderes também entram em conflito com os demais moradores da comunidade por permitirem a pesca esportiva de visitantes no interior dos lagos, controlando a entrada das pessoas e concentrando as possíveis rendas provenientes desta permissão de uso. Foi também identificada a existência de conflitos entre outras comunidades usuárias do sistema, que, no entanto, estão localizadas em áreas não contempladas pelo presente estudo.

Como mecanismos adotados em relação à apropriação do sistema Jacaré-Paracuúba, as comunidades têm proibido a pesca comercial no período de seca e a entrada de barcos pesqueiros que não pertençam às comunidades usuárias, controlando a entrada de pessoas no lago e a quantidade de pescado que pode ser retirada, e restringido a comercialização de algumas espécies.
Há ainda uma tentativa de viabilização da despesca do lago na seca, devido à grande mortandade de peixes neste período, sendo buscada a legitimação institucional por meio de portaria do Instituto Brasileiro do Meio Ambiente e dos Recursos Naturais Renováveis (IBAMA). Esta medida tem por objetivo o aproveitamento dos peixes residentes no lago ou dos que não se deslocam para o canal do rio durante a vazante, como forma de trazer recursos para as principais comunidades envolvidas.

Foi observado também que não existem proibições ou controle de acesso aos igapós durante o período de cheia, porém existem regras informais, pois os pescadores atuam de acordo com os limites da própria comunidade.

O sistema Cururu apresenta conflitos entre as comunidades que estão localizadas próximas ou nos paranás de acesso ao lago e as que estão situadas no interior deste. No auge do período de seca, há formação de poços que se tornam os únicos locais de conservação de água e

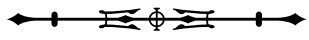


Tabela 3. Mecanismos adotados pelas comunidades estudadas em relação aos ambientes de pesca de uso comum.

\begin{tabular}{|c|c|c|c|}
\hline Sistemas & Comunidades & Conflitos & Mecanismos adotados \\
\hline Jacaré-Paracuúba & $\begin{array}{c}\text { São Geraldo } \\
\text { Nossa Senhora do Carmo } \\
\text { Cristo Ressuscitado }\end{array}$ & $\begin{array}{l}\text { líder x pescador comercial } \\
\text { líder + pesca esportiva x morador } \\
\text { morador x pescador comercial } \\
\text { entre comunidades usuárias }\end{array}$ & $\begin{array}{c}\text { Proibição de pesca comercial em } \\
\text { determinado período } \\
\text { Proibição de entrada de barcos } \\
\text { de pesca de fora } \\
\text { Controle de entrada no lago } \\
\text { Controle da quantidade capturada } \\
\text { Restrição de espécies para comercialização } \\
\text { Despesca } \\
\text { Busca de legitimação institucional } \\
\text { Regras informais sobre o uso dos igapós }\end{array}$ \\
\hline Cururu & $\begin{array}{l}\text { São Francisco do Canindé } \\
\text { São Francisco de Assis } \\
\text { Pentecostal } \\
\text { Nossa Senhora da } \\
\text { Conceição da costa do } \\
\text { Canabuoca e Fé em Deus }\end{array}$ & comunidade $\times$ comunidade & $\begin{array}{c}\text { Proibição de pesca comercial em } \\
\text { determinado período } \\
\text { Proibição de entrada de barcos } \\
\text { de pesca de fora } \\
\text { Controle de entrada no lago } \\
\text { Controle da quantidade capturada } \\
\text { Restrição de espécies para comercialização } \\
\text { Despesca } \\
\text { Regras informais sobre o uso } \\
\text { dos paranás e igapós } \\
\text { Acordo para barragem de lago }\end{array}$ \\
\hline Grande & $\begin{array}{c}\text { Paroá } \\
\text { Divino Espírito Santo } \\
\text { Bons Amigos } \\
\text { Menino Jesus } \\
\text { São Raimundo } \\
\text { São Sebastião }\end{array}$ & $\begin{array}{l}\text { comunidade } \times \text { comunidade } \\
\text { moradores } \times \text { fazendeiros }\end{array}$ & Acordo para barragem de lago \\
\hline
\end{tabular}

presença de peixes. O maior poço, porém, localiza-se em frente à residência de um líder comunitário, que restringe a pesca a poucas pessoas, mesmo para subsistência. Nesse sistema, entre os mecanismos adotados pelos comunitários encontram-se praticamente todos os anteriores, com regras informais de uso dos igapós e dos paranás, os quais estão disponíveis e são bastante explorados. Uma tentativa de controle da manutenção da produção no lago Cururu foi iniciada espontaneamente por moradores e usuários, inclusive das comunidades estabelecidas no interior. Para evitar a morte dos peixes provocada pela secagem do lago, foi também construída uma barragem com o objetivo de evitar a saída completa das águas, forma não autorizada de tentar garantir a pesca de subsistência.

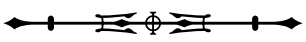


No sistema lago Grande houve conflito entre as comunidades usuárias durante uma tentativa de construção de barragem, gerado exatamente porque algumas destas não levaram o acordo inicial adiante. Outro conflito identificado foi entre moradores e fazendeiros, que alugam suas terras para pastagem.

As comunidades que fazem parte de cada um dos três grandes sistemas de lagos existentes na região estão desenvolvendo estratégias diferenciadas em relação ao uso dos pesqueiros. Observa-se que a pesca de subsistência está sendo praticada em todos os ambientes disponíveis para cada uma das comunidades, porém, a pesca comercial ocorre mais frequentemente nos ambientes considerados abertos, como rios, paranás e igapós.

Como consequência das características apresentadas e dos mecanismos citados, e como não existem diferenças estatísticas marcantes entre os períodos de seca e cheia, para o manejo integrado dos sistemas na área de estudo, são propostos três cenários de atuação, os quais subdividem a região fazendo-a coincidir com os três sistemas lacustres envolvidos e agrupando as comunidades usuárias de cada um deles (Figura 6).

O primeiro cenário estende-se dos lagos JacaréParacuúba até um pouco antes do paraná do Mari. Observa-se que a comunidade Cristo Ressuscitado é a que mais explora os ambientes com fins de comercialização, provavelmente devido ao maior número de pescadores envolvidos. Também há grande controle exercido pela Nossa Senhora do Carmo sobre a entrada dos lagos, que têm no paraná do Jacaré o único acesso ao rio Solimões. Os ambientes mais explorados comercialmente no segundo cenário, que engloba todo o lago Cururu e as adjacências, estendendo-se até o início do lago Inajá, são os paranás, exatamente pelas comunidades localizadas mais próximas a estes: São Francisco do Canindé e São Francisco de Assis. O lago Cururu está sendo explorado para comercialização somente por duas comunidades: Nossa Senhora da Conceição, da costa do Canabuoca, e Fé em Deus. O terceiro cenário agrupa os lagos de várzea. É o que mais está sendo explorado com fins de comercialização, mostrando que há maior flexibilidade no uso dos lagos, pois a proximidade da cidade de Manacapuru aumenta os interesses econômicos relacionados à venda do peixe, envolvendo maior número de usuários.

Todos os ambientes disponíveis e acessíveis a cada comunidade estão sendo explorados pela pesca de subsistência.

\section{DISCUSSÃO}

\section{O USO INTEGRADO DOS AMBIENTES DE VÁRZEA}

O manejo integrado de ambientes tem como objetivo fundamental a manutenção ou recuperação da integridade biológica do ecossistema (Sparks, 1995), garantindo sua sustentabilidade, o que também inclui dimensões sociais e econômicas (Berkes e Folke, 1998; Pomeroy e RiveraGuieb, 2006). Usuários de recursos naturais coletivos nem sempre se comportam segundo o argumento de Hardin (1968), em "A tragédia dos comuns", o qual pressupõe que as populações humanas em situações de livre acesso aos recursos promoverão colapso por sobre-exploração. A necessidade de conservação de áreas comuns tem possibilitado comunidades usuárias de um mesmo recurso a exercitarem seu poder de organização, definindo regras e formas de uso conjuntas, garantindo o equilíbrio do sistema do qual dependam diretamente (Berkes et al., 2006).

As populações ribeirinhas da Amazônia, em função da forte relação de dependência entre homem e meio ambiente, desenvolveram processo adaptativo que hoje culmina em uma combinação do uso integrado do espaço físico com o aproveitamento múltiplo dos recursos disponíveis (Junk, 1982, 1998; Furtado, 1993; McGrath et al., 1993b; Cerdeira et al., 1997; Batista, 1998; Batista et al., 1998a, 1998b). Tais processos adaptativos são oriundos mais comumente de difusão cultural (Morán, 1990; Richerson e Boyd, 1992) e, portanto, essa herança transmitida por meio da instituição familiar pode ser determinante para as características de uma sociedade.

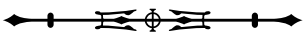




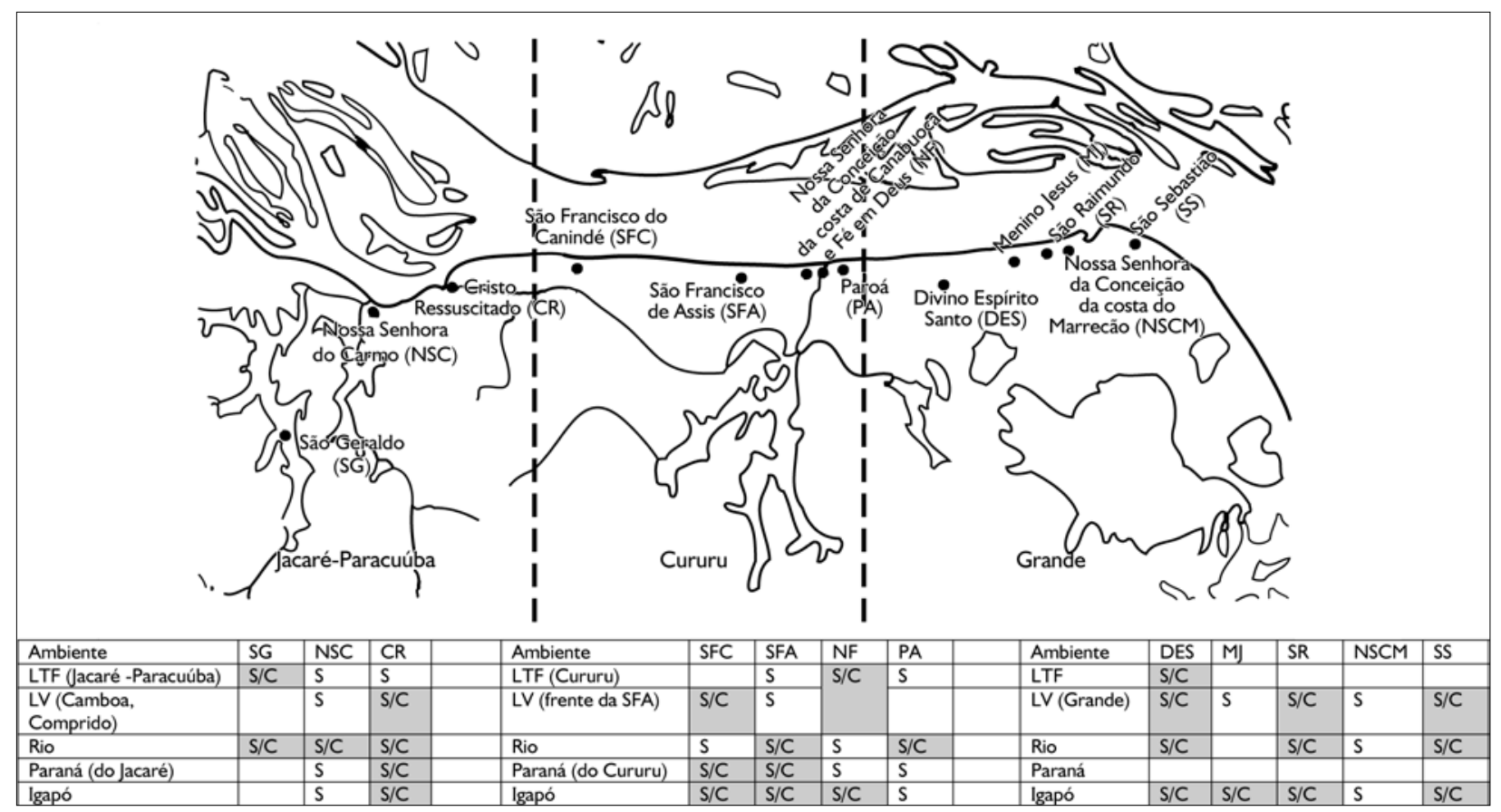

Figura 6. Cenários para o manejo integrado dos sistemas lacustres, baseados no tipo de pescaria praticada e nas comunidades usárias. Ambientes: LTF = lago de terra firme; LV = lago de várzea. Tipos de pescaria: $\mathrm{S}=$ subsistência; $\mathrm{C}=$ comercial.

\section{O USO DO SISTEMA: DISPONIBILIDADE}

\section{AMBIENTAL E COMPORTAMENTO TERRITORIAL}

Foi observada certa restrição quanto aos locais que poderiam ser explotados através de controle exercido pelos próprios comunitários e/ou usuários da unidade protegida, fazendo com que nem todos os locais de pesca, normalmente lagos, possam ser utilizados com fins de comercialização do pescado retirado, o que demonstra uma intenção de caráter conservacionista das áreas de subsistência.

$\mathrm{Na}$ área de amostragem, os ambientes de pesca (subsistência e comercial) estão sendo explorados por cada uma das comunidades, devido preponderantemente ao acesso e à proximidade da moradia do que pela busca diferenciada de espécies ou pelo rendimento das capturas. Assim, o uso desses ambientes nas costas do Canabuoca e do Marrecão está determinado pelas características fisiográficas que apresentam, sendo as capturas comerciais determinadas principalmente por disponibilidade de áreas de acesso e proximidade de centros para comercialização (Garcez et al., 2009).

$\mathrm{Na}$ costa do Canabuoca, os moradores exploram mais os pequenos lagos de várzea durante a seca do que os de terra firme (apesar da maior área destes), porque estes últimos diminuem seu espelho d'água em pelo menos $50 \%$ nessa época, provavelmente por estarem em nível superior ao canal do rio. Essas condições dificultam o acesso ao interior dos lagos; por outro lado, a pouca profundidade que eleva a temperatura diminui o oxigênio dissolvido na água, gerando grande mortandade de peixes. $\mathrm{Na}$ cheia, a exploração diversifica-se pela maior disponibilidade de áreas para a pesca. Na costa do Marrecão, os moradores exploram frequentemente o rio e os lagos de várzea, pois estes são numerosos no sistema lago Grande.

Ambos os tipos de pescaria estão ocorrendo em áreas demarcadas pelo espaço territorial da comunidade, sem grandes diferenças na frequência de exploração dos ambientes por período. Para a pesca de subsistência parece

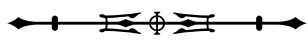


não haver restrições quanto ao uso dos pesqueiros pelos moradores da comunidade intitulada como proprietária do recurso ambiental, nem pelos pertencentes a comunidades próximas. Porém, a pesca comercial apresenta limites de atuação mais restritos territorialmente por meio de regras impostas informalmente por lideranças locais e moradores, pelo menos no período da seca. De fato, Garcez et al. (2009) identificaram fatores ambientais e econômicos como os que mais influenciam na pesca com fins comerciais nessa região. Em geral, os ambientes mais explotados foram aqueles que são caracteristicamente abertos e, portanto, menos sujeitos a controle.

De modo geral, as táticas frequentemente adotadas para regulamentação da atividade pesqueira aplicadas em demais áreas são: limitações do esforço de pesca empregado, das capturas, das espécies, do tamanho dos indivíduos, do período do ano e restrições no uso dos apetrechos ou das técnicas de pesca, além de restrição quanto à entrada de pescadores de fora da comunidade (Hilborn e Walters, 1992; McGrath et al., 1993a; Ruffino e Isaac, 1994; Batista, 1998; Isaac et al., 1998; Crampton, 1999; Da Costa et al., 1999; Pereira, 1999; Ruffino, 1999). Pode ainda haver divisão dos sistemas de lagos em zonas, com proibição da pesca de subsistência ou comercial, iniciando, assim, processos de manejo comunitário (Isaac et al., 1998; Ruffino, 2005; Berkes et al., 2006).

Os conflitos de pesca entre moradores das planícies inundáveis e pescadores comerciais provenientes de outras localidades cresceram bastante nas últimas décadas, devido à dificuldade de regulamentar a atividade pesqueira, principalmente quando relacionada à administração e ordenação pesqueira na Amazônia (Isaac et al., 1993; Estrada et al., 1996; Batista, 1998; Leonel, 1998; Mitlewski, 1999; Batista e Fabré, 2003). A introdução de novas tecnologias de captura, o desenvolvimento de pescarias comerciais e o crescimento demográfico têm sido as principais causas de conflitos (Barthem et al., 1992; Ruffino e Isaac, 1994; Ruffino, 2005) e, como resultado, as comunidades ribeirinhas começaram a desenvolver $\mathrm{e}$ implementar suas próprias regras de manejo, os chamados 'acordos de pesca', que servem para reger seus interesses particulares. Tais medidas representam formas populares de controle e acesso aos recursos, baseadas no manejo tradicional e nas experiências acumuladas pela própria população (Ruffino, 2005).

Desse modo, o manejo comunitário dos lagos pode ser uma estratégia bastante promissora para o desenvolvimento sustentável dos recursos da várzea no que diz respeito a formas locais de controle (McGrath et al., 1993a), mais eficazes no período de seca do que na cheia, quando há comunicação entre as águas. Exemplo desse tipo de manejo é a experiência vivida pela comunidade de Igarapé do Costa, baixo Amazonas, onde o tipo de pescaria permitida varia conforme as características ambientais dos locais pertencentes ao território da comunidade, assegurando o consumo por todo o ano e o complemento da renda familiar (McGrath et al., 1993a). Também as pescarias em lagos de Chino, uma vila no rio Tahuayo ao sul de Iquitos, Peru (McDaniel, 1997), e na Reserva de Desenvolvimento Sustentável Mamirauá, Amazonas, Brasil (Viana et al., 2007) passaram por processo de manejo comunitário. Durante o período de águas altas, a pesca em Chino é de caráter essencialmente aberto, com exceção à proibição feita aos barcos de pesca provenientes de Iquitos. Membros de comunidades vizinhas têm permissão para pesca, porém, quando as águas baixam, os lagos passam a ser de uso exclusivo da comunidade e o uso de malhadeira é proibido, bem como de métodos com venenos ou dinamites.

Pode ser observado que, dessa forma, a produção pesqueira estará sujeita não só a efeitos físicos, biológicos e ecológicos, mas também a fatores culturais, sociais e econômicos, os quais são limitantes da atividade pesqueira (Merona, 1990). Assim, as comunidades tentam buscar a melhor forma de aproveitar os recursos no seu entorno, retirando o necessário ao seu consumo e sustento de sua família e, por meio da adoção de mecanismos de apropriação de determinado local de 
pesca, tentam, de alguma forma, exercer cuidados sobre os recursos pesqueiros. Os acordos estabelecidos entre as comunidades para realização das barragens nos lagos exaltam a capacidade que as comunidades pesqueiras têm de se organizar (Pereira, 1999) e estão claramente vinculados à economicidade dos sistemas.

Apesar de a legislação de pesca determinar que o meio aquático e os organismos que nele habitam são de domínio público, sendo as propriedades coletivas de livre acesso, a demarcação do território especificamente relacionado aos lagos ocorre pelo fato destes serem áreas fechadas, importantes para a subsistência. Também pela relação direta observada pelos ribeirinhos, entre produtividade e pressão local de pesca (McGrath et al., 1993b). O conceito de ecologia econômica intrínseco nesse tipo de proposta que lida com a escassez de recursos, com a depleção do capital natural (Costanza, 1996) e com efeitos diretos nas opções disponíveis para os consumidores (Bettinger, 1991) deve, no entanto, garantir acesso dos moradores aos locais de pesca, pois esta é uma questão fundamental para a sobrevivência das comunidades (Leonel, 1998).

Identificou-se que lagos, paranás e igapós dentro dos limites territoriais das comunidades estudadas são as principais áreas nominadas como propriedade coletiva pelos membros no entorno. $\bigcirc$ uso e a consequente apropriação desses locais de pesca estão, portanto, relacionados à piscosidade de cada ambiente e à capacidade de responderem com uma produtividade pesqueira condizente com os limites de exploração efetuados pelos moradores, os quais intercalam e/ou alternam as espécies exploradas, por sua vez adaptadas a responderem rapidamente às mudanças ambientais a que estão sujeitas.

O sistema formado pelos lagos Jacaré-Paracuúba é utilizado sem restrições para alimentação pelas comunidades no entorno. Já a comercialização é controlada, exercida a proibição por poder imposto pelos líderes da comunidade Nossa Senhora do Carmo, os quais 'detêm' a entrada do lago. Este comportamento não contraria uma conduta em comunidades humanas: o status social desempenha papel importante na definição das regras de uso dos recursos (Begossi, 1998). Porém, existem objetivos particulares não vinculados à manutenção e conservação: o lago Jacaré é utilizado para pesca esportiva de tucunarés (Cichla spp.), peixe abundante neste ambiente e amplamente apreciado por este segmento. Todavia, a receita gerada se restringe a poucos envolvidos. Essa atividade merece estudos posteriores para avaliação de sua viabilidade e efetividade financeira como fonte geradora de divisas para toda a comunidade, bem como estudo aprofundado de suas implicações ecológicas.

As comunidades que exploram o segundo sistema, - lago Cururu, com dupla finalidade das pescarias, subsistência e comercial, têm por intenção a despesca do lago no período de seca, otimizando a receita com a venda e evitando perdas financeiras pela morte anunciada dos peixes. No entanto, essa proposta necessita do envolvimento de entidades e instituições governamentais.

As comunidades do terceiro sistema estudado, - lago Grande, já tentaram implementar medidas de contenção das águas de um dos lagos, no entanto, sem prosseguimento com a plena participação dos membros envolvidos. Pereira (1999) ressalta que o comportamento não cooperativo de alguns usuários pode ocorrer quando os limites de captura individual estão abaixo das expectativas de ganho econômico. Outro fato no sistema lago Grande é o uso das terras posteriores à comunidade para pastagem de gado, que, na maioria das vezes, não pertence a comunitários, sendo trazido por moradores de outras áreas, com a permissão de alguns membros da comunidade. Esse tipo de atividade, que é a principal ameaça para a planície inundável do rio Amazonas, provoca desmatamento e é devastadora para habitats de relevância ecológica para peixes (Goulding et al., 1996). Além disso, o gado consome grandes quantidades de macrófitas, as quais atuam como habitats de berçário para diversas espécies de peixes das várzeas, inclusive algumas de valor comercial (Sánchez-Botero e AraújoLima, 2002). Propostas que prevejam e evitem futuros 
conflitos na área são de extrema importância, devido ao uso em parceria dos sistemas disponíveis por grande número de comunidades de forte caráter pesqueiro.

Os trechos do rio Solimões pertencentes às áreas ocupadas por cada uma das comunidades também são bastante explorados, tendo como ponto favorável para uso a proximidade das residências e a alta abundância íctica, principalmente na seca. Porém, não foi observado como ambiente de uso restrito pelas comunidades proprietárias para a exploração pesqueira. Essa característica diferencia a região estudada de outras, onde o rio atua como forte delimitador de direitos de propriedade, principalmente nas pescarias dos grandes bagres migradores, onde o lanço tem forte poder determinador nas áreas de atuação dos pescadores (Fabré e Alonso, 1998; Rezende, 1999). Marques (1995) ressalta que na várzea da Marituba, região do baixo São Francisco alagoano, a territorialidade aquática é incorporada pelos pescadores em função da consciência sobre o valor econômico que tais áreas representam.

As florestas inundadas ou igapós são ambientes que merecem atenção destacada na região de estudo. São áreas de grande importância nas várzeas, pois nelas a fauna aquática dos principais rios procura refúgio na época das enchentes (Goulding, 1980, 1981) devido à vegetação arbórea produzir ampla variedade de frutos, fonte de alimentação para várias espécies de peixes, especialmente tambaqui (Colossoma macropomum) (Araújo-Lima e Goulding, 1998) e pacu (Mylossoma spp.), espécies bastante exploradas comercialmente pelas comunidades estudadas. Esse ambiente foi de particular interesse para todas as comunidades, sendo de extrema importância como fonte para a atividade pesqueira no período de cheia, tanto de subsistência quanto comercial, sendo explorado no espaço geográfico de cada uma. Dessa forma, avulta-se a necessidade de programas de manejo direcionados para a proteção e conservação desse espaço, garantindo a manutenção e, principalmente, evitando o desmatamento acelerado, um dos maiores problemas enfrentados nas regiões de várzea atualmente.
Estudos sobre a economicidade dos igapós da região e sua valoração ambiental também se fazem necessários.

\section{O MANEJO INTEGRADO DOS RECURSOS EM ÁREAS COMUNAIS}

A competição por espaço incide na defesa deste recurso, buscando o indivíduo reduzir a disponibilidade para os demais (Townsend et al., 2010). Como as comunidades ribeirinhas têm nos ecossistemas aquáticos e no peixe os fatores decisivos para a escolha dos espaços de maior concentração populacional, isto torna as áreas de várzea foco de disputas crescentes por seu controle (Leonel, 1998; Ruffino, 2005), gerando a necessidade de definir planos de manejo para o uso integrado dos sistemas.

Devido aos comportamentos territoriais já existentes na região, onde comunitários controlam a retirada de certos tipos de pescado ou limitam as finalidades de captura, a implementação de um programa de manejo pesqueiro teria o intuito de garantir a sustentabilidade do setor, evitando futuros conflitos, assegurando aos moradores acesso aos locais de pesca, organizando a exploração dos recursos e, consequentemente, viabilizando a possibilidade de complementação da renda familiar ao longo do ano (FAO, 2005).

Uma vez que os grupos de interesse na área de estudo já exercem por seus próprios meios o direito de uso dos sistemas aquáticos (lagos, paranás, igapós e rio) mais próximos, intitulando-se proprietários destes, propostas de manejo adequadas para a região devem ser examinadas do ponto de vista de cada grupo de comunidades envolvidas, devido à heterogeneidade dos usuários e dos objetivos de uso (Begossi, 1998; Junk, 1998).

As instituições (formas de controle que estruturam as interações humanas) devem lidar com dois problemas fundamentais de manejo que surgem como características básicas de todos os recursos disponíveis: como controlar o acesso ao recurso e como instituir regras entre os usuários para solucionar problemas de divergência entre a racionalidade individual e a coletiva (Berkes e Folke, 1998). O primeiro se refere ao problema da exclusão de

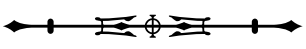


uma ou outra comunidade e/ou usuários, e o segundo ao substrato, ou seja, à determinação da intensidade de extração/exploração dos recursos.

$\mathrm{Na}$ região estudada, aspectos biológicos e socioeconômicos das pescarias estão fortemente relacionados. Estes são percebidos pelas normas existentes, como o controle de entrada nos lagos, a permissão de pesca de subsistência, mas nem sempre comercial, e pelo respeito entre comunitários, que limitam sua atuação de atividade pesqueira comercial às delimitações territoriais impostas geograficamente. Assim, para garantir o efetivo desenvolvimento das propostas de manejo, as unidades administrativas devem conhecer detalhadamente as atividades econômicas e formas de uso dos recursos naturais pelas populações (Begossi, 1998; Ruffino, 2005; Fernandes et al., 2009), além de definir os direitos de propriedade das comunidades envolvidas (Larkin e Sylvia, 1999; Berkes et al., 2006; Pomeroy e Rivera-Guieb, 2006).

As experiências na Amazônia sobre o manejo de recursos da várzea têm mostrado uma atenção focalizada sobre os sistemas lacustres. Porém, os resultados deste estudo indicam que as propostas e atitudes de manejo não devem estar unicamente voltadas à propriedade de lagos, mas sim estender-se às demais áreas onde haja comportamento territorial, nos diversos pesqueiros acessíveis aos núcleos populacionais. Como observado, planos de manejo para as áreas de várzea devem identificar previamente os comportamentos das populações, definindo cenários baseados na disponibilidade de ambientes e nas apropriações sobre os sistemas compartilhados.

Uma vez identificada a existência de comportamento territorial, o manejo comunitário dos sistemas abordados neste estudo deve estar atento às necessidades particulares dos grupos de interesse envolvidos, sem favorecimentos direcionados, mas sim com a preocupação de encontrar melhores meios de garantir o aproveitamento máximo dos recursos disponíveis, otimizando todas as formas de uso que tais ambientes possam proporcionar aos moradores ribeirinhos.

\section{CONSIDERAÇÕES FINAIS}

As comunidades estudadas exercem comportamento territorial em relação aos ambientes de pesca dentro de seus limites geográficos, havendo um respeito mútuo entre os moradores, que restringem a atividade pesqueira comercial à área ocupada pela comunidade.

Há sobreposição dos ambientes explorados pela pesca de subsistência e comercial, no entanto, nem todos os locais de comum acesso estão disponíveis para a atividade pesqueira praticada com fins de venda, demonstrando um caráter conservador em relação aos pesqueiros de subsistência.

Os igapós são ambientes de extrema importância para ambos os tipos de pescarias (subsistência e comercial), cujas capturas ocorrem dentro dos limites geográficos de cada comunidade. É relevante que haja investimento em projetos de valoração e conservação desses habitats.

Propostas de manejo integrado dos recursos aquáticos devem considerar em separado cada um dos sistemas estudados, o que mostra que, para a região amazônica, escalas geográficas de apenas 35 km de extensão, como a apresentada por este estudo, podem apresentar alta heterogeneidade de ambientes e interesses diferenciados dos diversos grupos envolvidos.

\section{AGRADECIMENTOS}

Os autores agradecem às instituições que apoiaram financeira e logisticamente este estudo: Instituto Nacional de Pesquisas da Amazônia (INPA), Programa Integrado dos Recursos Aquáticos e da Várzea (PYRÁ)/Universidade Federal do Amazonas e Conselho Nacional de Desenvolvimento Científico e Tecnológico (CNPq). Este estudo fez parte da dissertação de mestrado da primeira autora, defendida no Programa de Biologia de Água Doce e Pesca Interior do INPA.

\section{REFERÊNCIAS}

ARAÚJO-LIMA, C.; GOULDING, M. Os frutos do tambaqui: ecologia, conservação e cultivo na Amazônia. Brasília: Conselho Nacional de Desenvolvimento Científico e Tecnológico/Sociedade Civil Mamirauá, 1998. 
AYRES, J. M. As matas de várzea do Mamirauá. Brasília: Conselho Nacional de Desenvolvimento Científico e Tecnológico/Sociedade Civil Mamirauá, 1995.

BARTHEM, R. B.; PETRERE JR., M.; ISAAC, V. N.; RIBEIRO, M. C. L. B.; MCGRATH, D. G.; VIEIRA, I. J. A.; BARCO, M. V. A pesca na Amazônia: problemas e perspectivas para o seu manejo. Seminário sobre "Manejo de vida silvestre para a conservação na América Latina - Workshop e Seminários". Belém: 1992. 30 p.

BATISTA, V. S. Distribuição, dinâmica da frota e dos recursos pesqueiros da Amazônia Central. 1998. 291 f. Tese (Doutorado em Biologia de Água Doce e Pesca Interior) - Instituto Nacional de Pesquisas da Amazônia/Fundação Universidade do Amazonas, Manaus, 1998.

BATISTA, V. S.; FABRÉ, N. N. A pesca e o peixe na várzea: espaços, conflitos e conservação. In: RIBEIRO, M. O. A.; FABRÉ, N. N. (Eds.). Sistemas abertos sustentáveis - SAS: uma alternativa de gestão ambiental na Amazônia. Manaus: EDUA, 2003. p. 131-152.

BATISTA, V. S.; FREITAS; C. E. C.; INHAMUNS, A. J.; FREIREBRASIL, D. Os ribeirinhos e a pesca nas várzeas da Amazônia Central. Revista da Universidade do Amazonas. Série Ciências Humanas, v. 7, n. 1-2, p. 57-74, 1998a.

BATISTA, V. S.; INHAMUNS, A. J.; FREITAS, C. E. C.; FREIREBRASIL, D. Characterization of the fishery in river communities in the low-Solimões/high-Amazon region. Fisheries Management and Ecology, v. 5, n. 5, p. 419-435, 1998 b.

BEGOSSI, A. Property rights for fisheries at different scales: applications for conservation in Brazil. Fisheries Research, v. 34, n. 3, p. 269-278, 1998.

BERKES, F; MAHON, R.; MCCONNEY, O.; POLLNAC, R.; POMEROY, R. Gestão da pesca de pequena escala: diretrizes e métodos alternativos. Organização da edição em português D. C. Kalikoski. Rio Grande: Ed. Furg, 2006. 360 p.

BERKES, F.; FOLKE, C. Linking social and ecological systems for resilience and sustainability. In: BERKES, F.; FOLK, C. (Eds.). Linking social and ecological systems: management practices and social mechanisms for building resilience. Cambridge: Cambridge University Press, 1998. p. 1-25.

BETTINGER, R. L. Hunter-gatherers as optimal foragers. In: BETTINGER, R. L. (Ed.). Hunter-Gatherers: archaeological and evolutionary theory. New York: Plenum Press, 1991. p. 83-111.

CERDEIRA, R. G. P.; RUFFINO, M. L.; ISAAC, V. J. Consumo de pescado e outros alimentos pela população ribeirinha do lago Grande de Monte Alegre, PA - Brasil. Acta Amazonica, v. 27, n. 3, p. 213-228, 1997.

COSTANZA, R. Ecological economics: reintegrating the study of humans and nature. Ecological Applications, v. 6, n. 4, p. 978990, 1996.
CRAMPTON, W. G. R. Plano de manejo para o uso sustentável de peixes ornamentais na Reserva Mamirauá. In: QUEIROZ, H.; CRAMPTON, W. G. R. (Eds.). Estratégias para manejo de recursos pesqueiros em Mamirauá. Brasília: Sociedade Civil Mamirauá/ CNPq, 1999. p. 159-176.

DA COSTA, L. R. F.; BARTHEM, R.; CORREA, M. A. V. Manejo da pesca do tambaqui nos lagos de várzea da RDSM. In: QUEIROZ, H.; CRAMPTON, W. G. R. (Eds.). Estratégias para manejo de recursos pesqueiros em Mamirauá. Brasília: Sociedade Civil Mamirauá/CNPq, 1999. p. 142-158.

DUNN, T. Rapid Rural Appraisal: a description of methodology and its application in teaching and research at Charles Sturt University. Rural Society, v. 4, n. 3-4, p. 30-36, 1994.

DYSON-HUDSON, R.; SMITH, E. A. Human territoriality: an ecological reassessment. American Anthropologist, v. 80, n. 1, p. 21-41, 1978.

ESTRADA, M.; SILVA JR., R.; CORDEIRO, T. Un camino para una integración fronteriza amazónica: consideraciones para una propuesta de cooperación técnica entre Brasil y Colombia en los recursos pesqueros. In: XIMENES, C. (Ed.). Políticas pesqueiras nos países amazônicos. Belém: Associação de Universidades Amazônicas, Universidade Federal do Pará, Núcleo de Altos Estudos Amazônicos, 1996. p. 117-277. (Série Cooperação Amazônica, 17).

FABRÉ, N. N.; ALONSO, J. C. Recursos ícticos no Alto Amazonas: sua importância para as populações ribeirinhas. Boletim do Museu Paraense Emílio Goeldi, série Zoologia, v. 14, n. 1, p. 19-55, 1998.

FERNANDES, V. L. A.; VICENTINI, R. N.; BATISTA, V. S. Caracterização do uso de malhadeiras pela frota pesqueira que desembarca em Manaus e Manacapuru, Amazonas. Acta Amazonica, v. 39, n. 2, p. 405-414, 2009.

FOOD AND AGRICULTURE ORGANIZATION OF THE UNITED NATIONS (FAO). Increasing the contribution of small-scale fisheries to poverty alleviation and food security. Technical Guidelines for Responsible Fisheries. Rome: FAO, 2005. 79 p.

FURTADO, L. G. "Reservas pesqueiras", uma alternativa de subsistência e de preservação ambiental: reflexões a partir de uma proposta de pescadores do Médio Amazonas. In: FURTADO, L. G.; MELLO, W.; MELLO, A. F. (Eds.). Povos das águas: realidade e perspectivas na Amazônia. Belém: Museu Paraense Emílio Goeldi, 1993. p. 243-276.

GARCEZ, D. S.; SÁNCHEZ-BOTERO, J. I.; FABRÉ, N. N. Caracterização das pescarias de subsistência e comercial praticadas por ribeirinhos de áreas de várzea em Manacapuru, Baixo Solimões, Amazonas, Brasil. Boletim Técnico-Científico do Cepnor, v. 9, n. 1, p. 43-65, 2009.

GOULD, P.; WHITE, R. Mental maps. London: Penguin Books, 1974. $160 \mathrm{p}$.

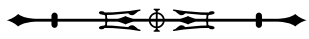


GOULDING, M. História natural dos rios amazônicos. Tradução de Antonio Carlos de A. dos Santos e Mirian Leal Carvalho. Brasília: Sociedade Civil Mamirauá/CNPq/Rainforest Alliance, 1997. 208 p.

GOULDING, M. Man and fisheries on the Amazon frontier. The Hague: W. Junk Publishers, 1981. 132 p.

GOULDING, M. The fishes and the forest. Berkeley: University of California Press, 1980. 280 p.

GOULDING, M.; SMITH, N. J. H.; MAHAR, D. Floods of fortune: ecology and economy along the Amazon. New York: Columbia University Press, 1996. 193 p.

HARDIN, G. The tragedy of the commons. Science, v. 162, p. 1243-1248, 1968.

HILBORN, R.; WALTERS, C. J. Quantitative fisheries stock assessment: choice, dynamics and uncertainty. Routledge: Chapman \& Hall, 1992. 570 p.

HOLLING, C. S.; BERKES, F; FOLKE, C. Science, sustaintability and resources management. In: BERKES, F.; FOLK, C. (Eds.). Linking social and ecological systems: management practices and social mechanisms for building resilience. Cambridge: Cambridge University Press, 1998. p. 342-362.

ISAAC, V. J.; RUFFINO, M. L.; MCGRATH, D. In search of a new approach to fisheries management in the middle Amazon region. In: THE INTERNATIONAL SYMPOSIUM ON FISHERY STOCK ASSESSMENT MODELS FOR THE $21^{\text {ST }}$ CENTURY, 21., 1998, Alaska. Proceeding... University of Alaska, Sea Grant College Program, 1998. p. 889-902.

ISAAC, V. J.; ROCHA, V. L. C.; MOTA, S. Considerações sobre a legislação da "piracema" e outras restrições da pesca da região do Médio Amazonas. In: FURTADO, L.; LEITÃO, W.; MELLO, A. F. (Eds.). Povos das águas: realidade e perspectivas na Amazônia. Belém: Museu Paraense Emílio Goeldi/MCT, 1993. p. 187-211. (Coleção Eduardo Galvão).

JUNK, W. J. A várzea do rio Solimões-Amazonas: conceitos para o aproveitamento sustentável e seus recursos. In: SIMPÓSIO DE ECOSSISTEMAS BRASILEIROS, 4., 1998, Águas de Lindóia. Anais... Águas de Lindóia: Max-Planck-Institut für Limnologie, 1998.

JUNK, W. J. Aquatic habitats in Amazonia. Switzerland. The Environmentalist, v. 3, supl. 5, p. 24-34, 1983.

JUNK, W. J. Amazonian floodplains: their ecology, present and potential use. Revista de Hydrobiologia Tropical, v. 15, n. 4, p. 285-301, 1982.

JUNK, W. J.; BAYLEY, P. B.; SPARKS, R. E. The flood pulse concept in river floodplain systems. Canadian Special Publication of Fisheries and Aquatic Sciences, v. 106, p. 110-127, 1989.
LARKIN, S. L.; SYLVIA, G. Intrinsic fish characteristics and intraseason production efficiency: A management - level bioeconomic analysis of a commercial fishery. American Journal of Agricutultural Economics, v. 81, n. 1, p. 29-43, 1999.

LEONEL, M. A morte social dos rios: conflito, natureza e cultura na Amazônia. São Paulo: Editora Perspectiva, 1998. 263 p.

LIMA, D. Diversidade socioambiental nas várzeas dos rios Amazonas e Solimões: perspectivas para o desenvolvimento da sustentabilidade. In: LIMA, D. (Org.). Diversidade socioambiental nas várzeas dos rios Amazonas e Solimões: perspectivas para o desenvolvimento da sustentabilidade. Manaus: IBAMA, ProVarzea, 2005. p. 337-386.

LIMA, D.; POZZOBON, J. Amazônia socioambiental. Sustentabilidade ecológica e diversidade social. Estudos avançados, v. 19, n. 54, p. 45-76, 2005.

MARQUES, W. J. C. Pescando pescadores: Etnoecologia abragente no baixo São Francisco alagoano. São Paulo: NUPAUB-USP, 1995. $285 \mathrm{p}$.

MCDANIEL, J. Communal fisheries management in the peruvian Amazon. Human Organization, v. 56, n. 2, p. 147-152, 1997.

MCGRATH, D. G.; DA SILVA, U. L.; CROSSA, N. M. M. A traditional floodplain fishery of the lower Amazon River, Brazil. Naga, The ICLARM Quatertely, p. 4-11, 1998.

MCGRATH, D. G.; CASTRO, F.; FUTEMMA, C. R.; AMARAL, B. D.; CALABRIA, J. A. Manejo comunitário da pesca nos lagos de várzea do Baixo Amazonas. In: FURTADO, L.; LEITÃO, W.; MELLO, A. F. (Eds.). Povos das águas: realidade e perspectivas na Amazônia. Belém: MCT/CNPq/Museu Paraense Emílio Goeldi, 1993a. p. 213229. (Coleção Eduardo Galvão)

MCGRATH, D. G.; CASTRO, F.; FUTEMMA, C. R.; AMARAL, B. D.; CALABRIA, J. A. Fisheries and the evolution of resource management on the lower Amazon floodplain. Human Ecology, v. 21, n. 2, p. 167-195, 1993b.

MERONA, B. Fish communities and fishing in a floodplain lake of central Amazonia. Bulletin d'Ecologie, v. 21, n. 3, p. 71-76, 1990.

MITLEWSKI, B. Metodologia do Levantamento Rápido Rural (LRR). Recursos pesqueiros do Médio Amazonas. Brasília: IBAMA, 1999. p. 166-187.

MORÁN, E. F. A ecologia humana das populações da Amazônia. Petrópolis: Ed. Vozes, 1990.

OSTROM, E. Governing the commons: the evolution of institutions for collective action. Cambridge: Cambridge University Press, 1990.

PEREIRA, H. S. Common property regimens in Amazonian fisheries. 1999. $119 \mathrm{f}$. Tese (Doutorado em Ecologia) - The Pennsylvania State University, USA, 1999. 
POMEROY, R. S.; RIVERA-GUIEB, R. Fishery Co-management: a practical handbook. Cambridge: International Development Research Centre, 2006.

REZENDE, L. F. B. Aspectos biológicos e pesqueiros da dourada (Brachyplatystoma flavicans) Pimelodidae-Siluroidei, em um setor da Amazônia Central. 1999. 76 f. Dissertação (Mestrado em Biologia de Água Doce e Pesca de Interior) - Instituto Nacional de Pesquisas da Amazônia/Fundação Universidade do Amazonas, Manaus, 1999.

RIBEIRO, M. O. A.; FABRÉ, N. N. Sistemas Abertos Sustentáveis (SAS): uma alternativa de gestão ambiental na Amazônia. Manaus: EDUA, 2003.

RICHERSON, P. J.; BOYD, R. Cultural inhenitance and evolutionary ecology. In: WINTERLALDER, B.; SMITH, E. A. (Eds.). Ecology, evolution and rural ecology. New York: Audine, 1992. p. 61-92.

RICKLEFS, R. E. A economia da natureza. 3. ed. Rio de Janeiro: Guanabara Koogan, 1996.

RUFFINO, M. L. Gestão do uso dos recursos pesqueiros na Amazônia. Manaus: IBAMA, 2005.

RUFFINO, M. L. Fisheries development in the lower Amazon river. In: PADOCH, C.; AYRES, J. M.; PINEDO-VASQUEZ, M.; HENDERSON, A. (Eds.). Várzea: Diversity, development and conservation of Amazonia's whitewater floodplains. New York: The New York Botanical Garden Press, 1999. p. 101-111. (Advances in Economic Botany, v. 13).

RUFFINO, M. L.; ISAAC, V. J. Las pesquerias del bajo Amazonas: problemas de manejo y desarrolo. Acta Biologica, Venezuela, $v$. 15, n. 2, p. 37-46, 1994.
RUFFINO, M. L.; MITLEWSKI, B.; ISAAC, V. J.; DE OLIVEIRA, P. R. S. Lago Grande de Monte Alegre: uma análise das suas comunidades pesqueiras. In: INSTITUTO BRASILEIRO DO MEIO AMBIENTE E DOS RECURSOS NATURAIS RENOVÁVEIS. Recursos pesqueiros do Médio Amazonas. Brasília: IBAMA, 1999. p. 31-75. (Série Estudos Pesca, coleção Meio Ambiente, n. 21).

SÁNCHEZ-BOTERO, J. I.; ARAÚJO-LIMA, C. A. R. M. As macrófitas aquáticas como berçário para a ictiofauna da várzea do Rio Amazonas. Acta Amazonica, v. 31, n. 3, p. 437-447, 2002.

SANTOS, G. M.; SANTOS, A. C. M. Sustentabilidade da pesca na Amazônia. Estudos avançados, v. 19, n. 54, p. 165-182, 2005.

SIOLI, H. Hydrochemistry and geology in the Brazilian Amazon region. Amazoniana, v. 1, n. 3, p. 267-277, 1968.

SPARKS, R. E. Need for ecosystem management of large rivers and their floodplains. Bioscience, v. 45, n. 3, p. 168-182, 1995.

TOWNSEND, C. R.; BEGON, M.; HARPER, J. L. Fundamentos em Ecologia. 2. ed. Porto Alegre: Artmed, 2010.

VERDEJO, M. E. Diagnóstico Rural Participativo: um guia prático. Brasília: Secretaria da Agricultura Familiar, 2006.

VIANA, J. P.; CASTELLO, L.; DAMASCENO, J. M. B.; AMARAL, E. S. R.; ESTUPIÑÁN, G. M. B.; ARANTES, C.; BATISTA, G. S.; GARCEZ, D. S.; BARBOSA, S. Manejo comunitário do Pirarucu Arapaima gigas na Reserva de Desenvolvimento Sustentável Mamirauá - Amazonas, Brasil. In: BLANC, D. (Org.). Áreas Aquáticas Protegidas como Instrumento de Gestão Pesqueira. Brasília: Ministério do Meio Ambiente/IBAMA, 2007. p. 239-261. (Série Áreas Protegidas do Brasil, v. 4). 